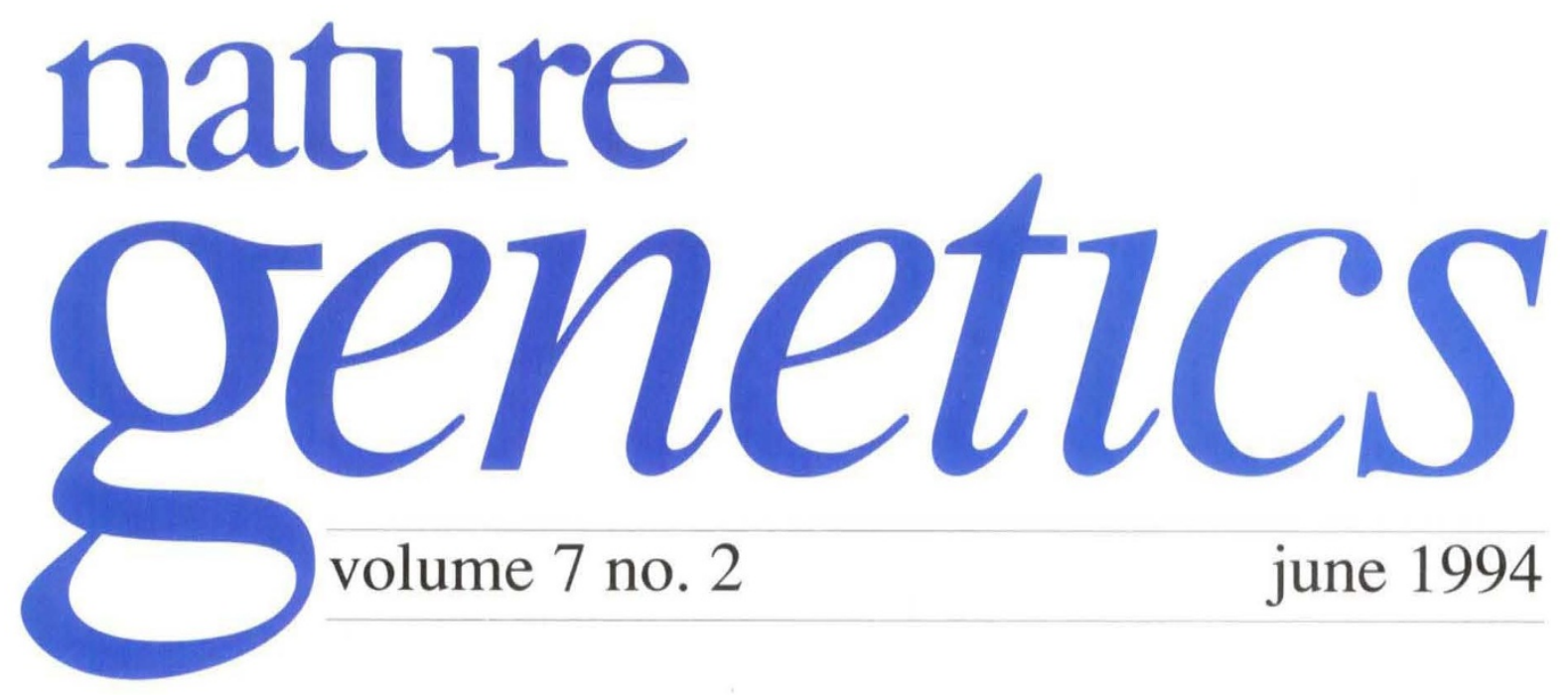

\title{
Genome centre comes together
}

Just off Convent Drive in Bethesda, Maryland, a sort of spiritual transformation is taking place in Building 49 on the sprawling campus of the National Institutes of Health (NIH) that has nothing to do with the well-publicized religious beliefs of one of its best-known inhabitants, $\mathrm{Dr}$ Francis Collins (who is a devout Christian). At longlast, the NIH has

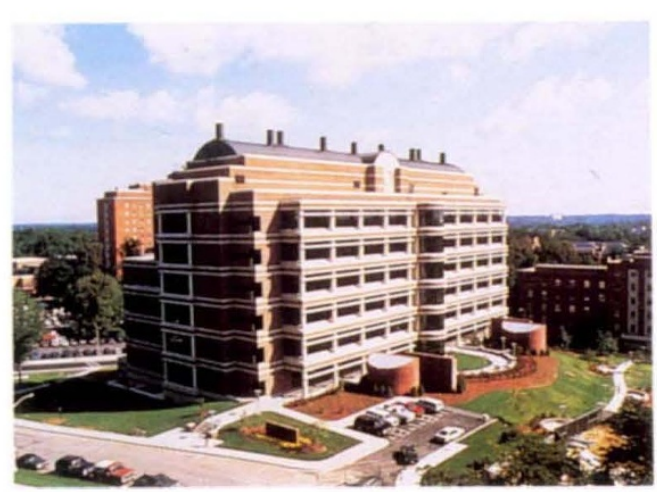

Fig. 1 The Silvio Conte Building, home of the intramural NCHGR division. an intramural research division devoted to genetics - part of the National Center for Human Genome Research (NCHGR) of which Collins is the director-that seems destined to produce some outstanding science if the calibre of its current recruits is anything to go by.

At a time when the intramural branch of the NIH is suffering from the widely held perception of lowered standards - the citation impact of NIH papers has declined steadily over the past 12 years and many high profile researchers have left recently - the infusion of new blood could not come at a better time. Since Collins was formally appointed to become Dr James Watson's successor as head of the genome project in April 1993, some
140 staffhave moved into the Silvio Conte Building (to give Building 49 its formal title; Fig. 1), and this is likely to rise eventually to about 200 people.

Thanks in large measure to Collins' reputation and considerable powers of persuasion, a distinguished cadre of researchers is being lured to the new centre in what Bernadine Healy, the then director of NIH, described a year ago as "a critical example of the reversal of the NIH brain drain". One of the new senior investigators in the research programme, which is divided into six main sections (Fig. 2), is Dr Michael Blaese. Best known for his leading role in the first gene therapy trials for adenosine deaminase deficiency, he has moved across campus to run the Clinical Gene Therapy Branch. But the remaining five research heads, all of whom are familiar names within the genetics community, have come from outside the NIH. Dr Jeffrey Trent (director of the Division of Intramural Research and also head of the Laboratory of Cancer Genetics) came with Collins from the University of Michigan. After ten years at the University of Pennsylvania, Dr Robert Nussbaum was appointed chief of the Laboratory of Genetic Disease Research. Dr David Ledbetter (Diagnostic Development Branch) left the Baylor College of Medicine in Houston, and Dr Clair Francomano (Medical Genetics Branch) is expected to move from the Johns Hopkins Hospital in Baltimore. Collins himself runs the curiously named Laboratory of Gene Transfer, even though 


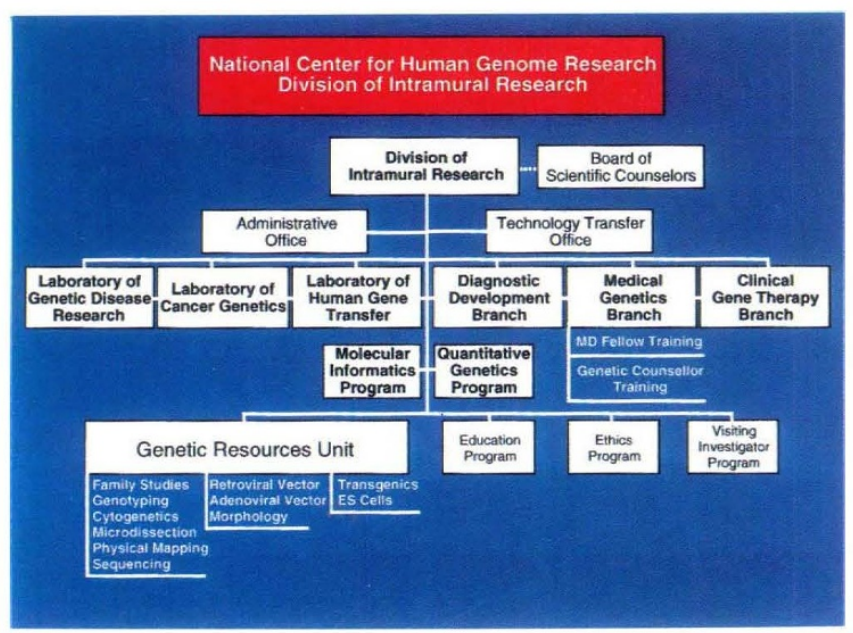

Fig. 2 Genome centre genealogy. The NCHGR Division of Intramural Research is divided into six main sections, three research-based laboratories and three clinically linked branches.

most of his group are studying the molecular basis of genetic diseases including breast cancer and leukaemia. Among other notable scientists who may soon be joining the centre is Dr Mark Hughes, a former colleague of Ledbetter's at Baylor and a pioneer of preimplantation diagnostic procedures (see Nature Genetics 6, 1-2; 1994). Most of his clinical research would be conducted at a perinatal clinic in the nearby Georgetown University Medical Center, in Washington DC.

The considerable expertise already assembled at the NCHGR focuses largely on the search for disease genes, ranging from positional cloning and gene mapping to state-of-the-art fluorescence in situ hybridization and microdissection techniques. There will also be a strong leaning towards mouse studies - Nussbaum's group, for example, plans to produce mice deficient for several key enzymes in the inositol phosphate signalling pathway. But one of the most important long-term priorities for future development is the desire to focus on complex trait analysis, now that so many of the more common single gene disorders have been characterized. Collins' group is, of course, best known for having cloned several of these disease genes, but he is already working towards his next goal (after breast cancer, that is), namely the search for loci involved in type II diabetes. The major targets of this intitiative, however, are genes responsible for cancers and mental illness, to which end NCHGR hopes to develop close ties with the National Institute of Mental Health, which is experiencing tough budget cuts and signs of flagging morale. Closely linked with the emphasis on polygenic diseases is the need to develop greater expertise in computing and molecular informatics, as well as genetic epidemeology.

Services rendered: One of the most valuable (and popular) services due to be offered by the NCHGR is likely to be the Visiting Investigator Program - indeed some members of the NCHGR Advisory Council, such as Stanford's David Botstein, view it as an essential component of the centre. The programme will allow senior scientists at other institutions to spend 3-12 months in the NCHGR laboratories, to avail themselves of new technologies or to forge new research interests and collaborations. It is due to commence at the beginning of 1995 . In addition to its research activities, the centre will also pursue a vigorous programme of training, ethical and educational programmes. For example, the Medical Genetics Branch will organize training courses for genetic counsellors, culminating in a master's degree. This is an urgently needed requirement in view of the dilemmas over screening raised by the recent and imminent discovery of major cancer-causing genes. There is also a strong commitment to expand research into the ethical and legal issues that these new developments will generate.

At present, the NCHGR intramural programme claims only a modest $1.7 \%$ of the $\$ 1.3$ billion intramural NIH budget, although this will probably increase to about $3 \%$. The centre is likely eventually to become a full institute within the NIH, a move Trent says is "highly desirable" but not a priority. The centre already has full control over its hiring decisions, which is one of the more tangible benefits of being an institute.

It is impossible to miss the unbridled enthusiasm that Collins and the rest of his colleagues share as they contemplate the many possibilities ahead of them. But at a time when much of the NIH is beset with internal problems, they do not wish to give the impression that they have received special treatment. Collins is quick to point out that many of the principal group leaders now at NCHGR, including himself, have made significant sacrifices in the process of joining the federal payroll. Many left well-endowed professorships, excellent charitable funding and usually considerably more space than they now have. There are notably fewer perks as government employees too-Collins himself has been ticketed for leaving his motorbike illegally parked outside the building. 